\title{
A EXPERIÊNCIA DO REAL: UM LEITURA DE "OS TRÊS NOMES DE GODOFREDO" SOB A PERSPECTIVA DO INSÓLITO FICCIONAL
}

SILVA, Luciana Morais da ${ }^{29}$

\begin{abstract}
Desaparecendo os limites do mundo ficcional, necessário à ilusão realista, há uma mudança do estatuto da representação: mais importante do que narrar alguma coisa é o próprio processo de narrar.
\end{abstract}

(BELLA JOZEF, 2006, p. 176)

O presente trabalho tem por objeto o conto "Os três nomes de Godofredo", de Murilo Rubião, texto em que o "insólito se apresenta sob as mais diversas formas" (COVIZZI, 1978, p. 29). O autor elabora uma narrativa que se passa em um lugar comum, um espaço qualquer nas ruas e na vida de uma grande cidade. Entretanto, as relações que permeiam sua ficção ultrapassam o sólito, com homens e mulheres aparentemente desconhecidos, mas que interagem por uma relação conjugal.

A narrativa rubiana apresenta um narrador autodiegético, ou seja, um edifício de palavras (Cf. BRAIT, 1985, p. 10), que relata suas próprias experiências, contando-as como personagem central da narrativa, uma vez que este estrutura o tempo, a distância e a própria constituição da diégese (Cf. REIS, 2000, p. 259). Consoante Carlos Reis (2000, p. 257), o narrador, diferente do autor, uma entidade empírica, é uma entidade fictícia, a quem, cabe a tarefa de enunciar o discurso, no cenário da ficção.

29 Mestranda em Letras - Literatura Portuguesa - pela Universidade do Estado do Rio de Janeiro, sob orientação do Prof. Dr. Flavio García, e em Letras Vernáculas - Literaturas Africanas d Língua Portuguesa - pela Universidade Federal do Rio de Janeiro, sob orientação da Prof. ${ }^{a}$ Dr. ${ }^{a}$ Maria Teresa Salgado. 
A ficção se desenvolve em torno de um narrador-personagem denominado Godofredo, esse delineado como um homem que casa diversas vezes. Tais casamentos são pouco proveitosos, principalmente quando se observa a forma prematura como ocorreram seus desfechos, pois o homem após casar logo ceifa as vidas de suas esposas. A morte talvez seja uma saída para a infelicidade proveniente de um quotidiano monótono, já que há sempre uma novidade em suas relações. Todavia, a narrativa não apresenta indícios da uniformidade da convivência, pois o esquecimento e a renovação de suas relações tornam o tempo fugidio e a vida "alucinada".

Cada mínimo elemento desenvolvido na narrativa envolve uma apropriação do evento insólito e seu aproveitamento, porque a personagem mesmo que aparentemente transtornada pelas "novidades", que, em geral, fogem as expectativas quotidianas, as aceita e até mesmo se beneficia delas. Assim, "não somos lançados ao caos mas a uma especial ordenação do caos" (COVIZZI, 1978, p. 31), com uma história marcado por eventos que transtornam a realidadeintradiegética.

O insólito, que serve de móvel para o desenvolvimento da narrativa, carrega uma "carga de indefinição própria de seu significado" (COVIZZI, 1978, p. 26). A acepção mais comum do termo refere-se ao "sentimento do inverossímil, incômodo, infame, incongruente, impossível, infinito (...), inaudito..." (COVIZZI, 1978, p. 26), ou seja, aquilo que ultrapassa o limite do natural e ordinário. De acordo com o próprio Rubião, a partir da reprodução de suas palavras por Sandra Nunes, "é mais fácil aceitar o onírico que os absurdos do real, pois o irreal e a fantasia parecem ser mais verdadeiros que o cotidiano" (NUNES,s.n).

O conto apresenta uma diversidade de elementos insólitos, mas um dos principais acontecimentos que fogem ao natural, ao ordinário, ao esperado, ocorre no segundo parágrafo, visto que não é comum 
um homem sentar-se por quinze anos em um mesmo lugar para jantar, e, repentinamente, se dar conta que, a partir de um tempo indeterminado (não-definido, vago), uma desconhecida tenha se sentado a sua frente sem que ele nem ao menos tomasse conhecimento:

De uma data que não poderia precisar, todos os dias, ao jantar e ao almoço, ela sentava-se à minha frente na mesa onde por quinze anos seguidos fui o único ocupante.

Ao me certificar da sua constante presença, considerei o fato perfeitamente natural. (RUBIÃO, 2005 , p. 87 , negritos nossos)

Nota-se uma falta de preocupação da personagem, que aproveita a companhia da mulher a sua frente sem se incomodar com esta presença, a qual, em um primeiro momento, parece não ter sido convidada;porém, posteriormente, ele mostra um interesse relacionado ao bem estar de sua "vizinha" (RUBIÃO, 2005, p. 87). A moça poderia se incomodar com o constante comparecimento do homem e, por isso, ele decide procurar uma nova mesa, declarando: "notei serem numerosos os lugares vagos" (RUBIÃO, 2005, p. 87). Tanto o não reconhecimento da companheira de refeições quanto ainusitada vontade de prevenir estar incomodando são marcas do insólito, pois as reflexões do narrador ocorrem de repente, sem aviso, instaurando uma aura meta-empírica.

A personagem também de modo "inverossímil" não se preocupa com a ausência de pessoas, ou o com o número reduzido, sendo explicada depois, ao contrário, ela apenas se apropria do observado e se revolta por ter que deixar seu lugar por uma estranha. A moça, causando um estranhamento na personagem-narrador, o segue até sua nova mesa e ele enfocando seu "incômodo" a questiona sobre o convite para o jantar:

- Claro! E não havia necessidade de um convite formal para me trazer aqui. 
- Como?

- Bolas, desde quando tornou-se obrigatório ao marido convidar a esposa para as refeições?

- Você é minha mulher?

- Sim, a segunda. (RUBIÃO, 2005, p. 89)

A conversa remete ao caráter insólito da narrativa, pois ela ser a esposa dele claramente o assusta, visto que ele não a reconhece como tal, afinal, nem sabe quem ela é. Os elementos se conjugam e indicam uma narrativa pautada pela irrupção do insólito ficcional.Os estranhamentos e a denúncia dos eventos inauditos são possibilitados pela dúvida do narrador, que clareia as irrupções do incomum por meio de um constante esquecimento, já que se impressiona com a companheira de refeições, mas sem reconhecê-la como cônjuge.

A mulher, ao invés de reivindicar seu papel de esposa, entra no diálogo insólito, permitindo uma visualização da misteriosa relação.No decorrer do conto a companheira de mesa, que é a segunda esposa, banaliza o assassinato da primeira, tornando o homicídio (fomentado pelo ciúme, pela busca da fidelidade) - que ele faz questão de não querer ouvir: "- Não me fale do crime" (RUBIÃO, 2005, p. 89) -, algo comum, corriqueiro.

Godofredo, já bastante, confuso por não se lembrar nem ao menos de ser casado, ou que dorme com ela em um mesmo apartamento e cama, desconhece a companheira, preferindo não tomar nem consciência do crime que esta descreve 0 isentando. $O$ narrador só se apropria de sua relação com a mulher, e da situação, para poder ter sensações a respeito da nova mulher, de quem nem ao menos se lembrava:

Já deitado, sentindo o calor daquele corpo, veiome intensa sensação de posse, de posse definitiva. Não mais podia duvidar de que ela fora minha. Baixinho, quase sussurrando, Ihe falei longamente, os seus cabelos roçando no meu rosto. (RUBIÃO, 2005, p. 91) 
O desejo "confirma" o casamento e a insegurança inicial se dissipa diante dos prazeres da morada e da esposa, assim, a curta passagem de tempo - "os meses se aligeiravam" (RUBIÃO, 2005, p. 92) - indica que, a personagem até mesmo reconhece que sabia o nome de sua mulher Geralda, desvendando sua casa como um ambiente acolhedor e aconchegante para viver suas intimidades, isso ao observar na estranha uma companheira com a qual troca carícias e divide o leito.

O narrador, aparentemente cheio de cuidados para com seu cônjuge, percebe a passagem dos dias, e sente a força desestruturadora da rotina, do tédio e, até mesmo, da impossibilidade de estar só, acarretando em um ser torturado que acaba por considerar a saída derradeira. A convivência com a esposa que inicialmente não conhecia, mas que agora o sacia, é ao mesmo tempo prazerosa e rotineira, dessa forma, a saída possível é o assassinato da companheira, uma liberdade possível em uma relação que estranhamente $o$ angustia.

A personagem Godofredo, ou João de Deus, como é chamado por Geralda, é um ente insólito, visto que não se lembrava de sua esposa, e repentinamente se relaciona com ela, sabendo até mesmo seu nome. O homem, aparentemente feliz por tê-la ali para satisfazer seus impulsos sexuais, é o que almeja matá-la por se sentir sufocado pela presença da esposa. Ao perceber a insatisfação do esposo e a vontade deste de enforcá-la, a estranha esposa, nada objeta, senão que Ihe dá seu pescoço em uma apatia insólito, como se nota:

Enxerguei uma corda dependurada num prego. Agarrei e disse para Geralda, que se mantinha abstrata, distante:

- Ela Ihe servirá de colar. Nada objetou (...) Em seguida puxei as pontas (...) como se estivesse recebendo uma carícia. Apertei com força o nó e a vi tombar no assoalho. (RUBIÃO, 2005, p. 92-93) 
O desfecho da relação de João de Deus e Geralda apresenta traços cruéis, os quais caracterizam a submissão da mulher ao homem por um viés de insólita impassibilidade. O narrador planeja um assassinato, vestindo-a antes mesmo do efetivo enforcamento por um manto soturno de morte e aridez de sentimentos, já que cria a imagem da corda que ceifaria sua vida como um colar, um presente.

Há na narrativa o maquinal desejo do narrador em exterminar a companheira que de certa forma o fazia mal, porém não se sabe a natureza de tal privação de liberdade, que o levasse a tirar a vida de outra pessoa. O homem só comete o crime para retroceder ao estado livre de outrora. Aparentemente culpada por privá-lo da liberdade de solteiro, a esposa Geralda não discute ser assassinada, aceitamorrer. E ele, por sua vez, não sente nenhum remorso por colocar a corda no pescoço da mulher, sendo esta a esposa descoberta e cobiçada de antes.Aliás, o homem preocupa-se basicamente em rumar para sua habitual refeição no restaurante quotidiano, pois almejava retornar à liberdade, buscando a mesa usual.

Pensando-se a respeito da composição do insólito, observa-se que não é normal ou lógico a ausência de sentimentos de quem morre e de quem mata, pois tanto o algoz quanto a vítima estão ou são envolvidos pelo crime, mas na narrativa as mulheres se entregam irremediavelmente. Ao confrontar os limites entre o sólito e o insólito, as personagens, principalmente, as esposas serviram como entrelaçamento entre o passado esquecido e o presente incomum, visto que o narrador aceita recordações, mas despreza ficar preso em "casamentos".

Outro elemento inaudito na narrativa é o nome João de Deus, dado ao narrador por sua insólita segunda esposa, que, posteriormente, se verificará como insólito, pois a personagem afirma se chamar Godofredo.O homem declara-se como Godofredo frente a sua primeira esposa Joana, descrita como morta, que volta 
insolitamente, e Ihe chama Robério, nome pelo qual ele não se reconhece e ainda questiona: - Robério?! (Em tempo algum me conheceram por esse nome. Havia um erro, um tremendo engano em tudo aquilo.) (RUBIÃO, 2005, p. 93).

Nem como Robério, nem João de Deus, a personagem deseja ser reconhecida como Godofredo, pois, é alguém que se apropria dos acontecimentos insólitos de seu quotidiano, descartando-os diante do menor infortúnio. O narrador-personagem revela os acontecimentos narrativos a partir de seu olhar sobre os "fatos", descrevendo seu quotidiano a partir de sua apropriação ou não das esposas que o circundam, usando-as como objetos quando necessário. Estranhamente o encontro com as esposas é tão insólito como a forma pela qual elas saem de sua vida, já que ele não se incomoda com suas companheiras desde que não o privem de sua "liberdade" de permanecer em uma mesma mesa, no restaurante de sempre.

O leitor hesita diante de uma "morta" em franco diálogo com seu marido, o qual não há reconhece, ainda que esta aparentemente saiba quem ele é, mesmo que o chamando por um nome desconhecido. Entretanto, o narrador só almeja se livrar da situação, sem nenhuma reflexão mais detida a respeito do acontecimento, uma vez que para ele seu nome não é Robério, mas Godofredo. Observase, assim, uma ruptura da lógica, com personagens que demonstram saber quem é o narrador, porém o reconhecem não como o homem que tem em sua frente, mas como outro.

Dessa maneira, as relações indicam uma transitoriedade do mundo reconhecido pelo senso comum como normal, haja vista, a banalização da morte, dada como um presente, e não percebida pela cessação da experiência do viver. Os elementos narrativos se conjugam, indicando o mundo não sólito, em que as relações são efêmeras e provenientes do esquecimento e do desejo. O narrador lembra-se das esposas por desejá-las, mas retira-lhes a vida por considerá-las um empecilho para o pleno gozo da liberdade. 
Todavia, não existe no texto uma explicação natural ou sobrenatural para a reaparição da primeira esposa, sabidamente morta, ou para a efetiva causa do assassinato da segunda. O narrador apenas relata seus encontros, sem nem ao menos identificar como as esposas sabem dos assassinatos cometidos. A primeira esposa, então, que retorna após a morte da segunda, é ainda mais misteriosa, uma vez que aparentemente morta, sabe do enforcamento de Geralda. A narrativa apresenta a morte como saída para a privação da liberdade e as personagens que convivem com o narrador como elementos coadjuvantes para a realização de suas pulsões, tendo uma condição insólita.

Não há, assim, na narrativa uma referência, coerente e real, do local por onde a primeira esposa esteve, de quanto tempo se passou, de onde ela veio, de como chegou àquele restaurante e de como tem tanto acesso a vida de um marido que nem a reconhece. A ficção se elabora pelas lacunas deixadas pelo escritor, que tornam o narrador uma personagem insólita, já que presente na vida das mulheres as confunde perdido em um tempo também incomum, afinal, as idas e vindas ocorrem sem noção de tempo, ou espaço. Os reencontros têm como plano de fundo o restaurante, os encontros e o esquecimento, que se bifurcam por uma efemeridade das relações.

Os crimes, presentes na narrativa, mantêm um padrão no que diz respeito à motivação. Eles oferecem uma explicação com base no ciúme desmedido e sem razão, passional ou coerente, sendo justificados e apoiados pelas mulheres, as quais, ao invés de temerem, aceitam e confortam o seu possível algoz. As esposas não se importam com o assassinato por enforcamento, apenas 0 constatam, de modo irreal, e se apropriam do ocorrido para convencer a personagem, dizendo que é o cônjuge delas. Assim, até mesmo o assassinato é apropriado para se garantir a posse do outro. $\mathrm{O}$ homem atende as esposas pelo desejo despertado e as mulheres pela sublimação dos aparentes problemas conjugais. 
A falta de respeitoàs relações humanas e ao prematuro "esquecimento" de um assassinato, relatado de forma trivial, enfatiza um questionamento acerca dos limites entre osólito e o insólito, uma vez que: "sentimos que as sólidas formações sociais à nossa volta se diluíram." (BERMAN, 1987, p. 90). Dessa forma, nota-se que as formações sociais na maioria das vezes tendem a punir os criminosos, apesar disso, a morte prematura de uma jovem, ou de duas, não tem a menor importância, já que a "narrativa continua". Mostra-se, então, uma dissolução das relações, sem questionamento o homem almeja liberdade e as esposas apenas tê-lo, seja morrendo, seja vivendo.

Sendo assim, nota-se uma estruturação do insólito focado na apropriação da presença feminina por parte do narrador e um desprezo ao lógico, ao esperado. Afinal, a personagem se deleita com o carinho dado pela dita "segunda esposa", sem respeitá-la, pois ao sentir-se entediado, a enforca sem o menor remorso e volta a sua vida quotidiana. "Godofredo" demonstra se incomodar apenas com aparência de suas esposas:

Na cadeira defronte à minha acabava de assentarse uma jovem senhora que, não fossem os cabelos louros, juraria ser minha esposa. A semelhança entre elas me assombrava. Os mesmos lábios, nariz, olhos, o modo de franzir a testa. (RUBIÃO, 2005, p. 93)

Em vista dos comentários elaborados e dos questionamentos estruturados até aqui, observa-se os pontos de aproximação e distanciamento da narrativa se comparada às pertencentes aos diferentes gêneros literários. A curta memória da personagem, que tem três nomes, "três vidas", remete ao modo como esta diégese se constrói em torno de eventos insólito, móveis da narrativa, contudo, é necessário o questionamento a respeito do gênero ao qual o conto poderia se filiar? 
O fantástico, ou seja, a "ruptura da ordem reconhecida, irrupção do inadmissível no seio da inalterável legalidade quotidiana" (CAILLOIS - apud FURTADO, 1980, p. 19), é um gênero ao qual Rubião costuma ser vinculado, porém, apesar do traço do narrador autodiegético, as personagens não hesitam entre a realidade e sonho, ou entre verdade e ilusão (Cf. TODOROV, 1992, p. 30), os eventos incomuns ocorrem e não há questionamento sobre sua natureza.

Outro gênero é o Maravilhoso, o qual remete a mirabilia, ou seja, coisas admiráveis, isto é, que fogem ao curso natural das coisas e do mundo (Cf. CHIAMPI, 1980, p. 48), no qual fica claro que a narrativa não pertence, pois apesar de ocorrer um evento insólito, como não lembrar que cometeu um assassinato, é evidente nesta criação literária que não há a intervenção de seres sobrenaturais, os quais interfiram de forma a causar no ouvinte ou leitor surpresa, arrebatamento, admiração etc. (Cf. CHIAMPI, 1980, p. 49). O insólito é claramente apropriado e a personagem não se admira, apenas o aceita, já que também é um ente incomum devido ao seu continuo esquecimento.

Segundo Todorov (1992), o gênero fantástico está no limite entre o maravilhoso e o estranho, porém o que ele considera como estranho, seria uma composição narrativa marcada pelo desfecho empírico, em que há a ocorrência de um evento insólito, mas tendese para uma explicação racional, que consideraria o evento como estranho, mas perfeitamente normal. A narrativa, ao contrário, apresenta um leque de eventos insólitos, porém nem se busca explicações para o inusitado, nem se hesita diante de sua irrupção, há apenas sua denúncia e, posterior, acomodação.

A forma com que os eventos insólitos pululam na narrativa remete, ainda, ao gênero do realismo maravilhoso, porém não existem duas realidades conflitantes, apenas uma, parasitária do mundo real, rompida por um evento insólito. À semelhança da realidade empírica, os eventos inauditos, a começar pelo narrador, 
podem ser observados como elementos de uma sociedade em crise, já que a própria personagem, ao não se lembrar de nada, aproveitase da apatia das estranhas esposas para se transformar em vários, fragmentos de um homem também incompleto.

A irrupção do insólitona narrativa aponta para a constituição de um texto híbrido, em que o narrador autodiegético constantemente se apresenta em um enfrentamento com o quotidiano. João de Deus, Robério e, finalmente, Godofredo, constituem um homem que encontra o benefício de desconhecer seu passado, além das delícias de se descobrir "cercado" ou ao menos sempre acompanhado de belas esposas, isto é, mulheres que o aceitam e o reconhecem como seu, enquanto ele se aproveita das circunstâncias, sem dar real valor aos desdobramentos de suas "decisões".

O narrador-personagem mata sem se lembrar, a mulher volta após o assassinato de uma outra, todas se intitulando esposas, e, ainda assim, ele se apropria do casamento, aproveitando suas delícias e desprezando o homicídio. Da mesma maneira que as demais personagens, ele não se importa, nada acontece, ninguém se desespera, ou se emociona.

O narrador ainda encontra uma moça, sua suposta "noiva", começa tendo um pequeno estranhamento, mas, logo, ele se apropria da ideia de uma nova companhia; afinal, ele poderia descobrir um novo passado em sua mente, como já ocorrera,isso escolhesse o caminho das indagações. Então, o homem reflete:

Ocorreu-me formular algumas perguntas, possivelmente as mesmas que fizera a minha segunda mulher, naquela noite, no restaurante. Desisti, preocupado em redescobrir uma cidade que se perdera na minha memória. (RUBIÃO, 2005, p. 95)

Há no conto a consolidação das constantes insólitas, que confrontam o esperado, e sua acomodação, pois "Godofredo" não tem 
reais lembranças e quando as têm, sabe que matou, torna isso algo comum, incorporando o fato, assim como a mulher, ao quotidiano.

O insólito, ou meta-empírico, como afirma Furtado (s.a.), em verbete sobre o fantástico modal, é um traço comum a diversos gêneros canônicos; porém, é a resposta a irrupção do evento incomum, que define a pertença ou não de uma narrativa a dado gênero. O surgimento de um evento insólito e sua aparente banalização pelas personagens, as quais estranham que algo tenha acontecido, mas se apropriam dos elementos incomuns, acarreta na percepção da hibridez narrativa, composta por traços diversos.

Nesse sentido, o homicídio e 0 adultério não são problematizados pelas personagens como um elemento conflituoso. $\mathrm{Na}$ atualidade, os atos cruéis, que põe em jogo o direito de ir e vir de qualquer humano, podem, também, ser considerados insólitos, pois colidem com os valores sociais. Ainda que a maldade seja comumente veiculada, é sabido que o assassinato e o adultério são desvios, rupturas, próprios de uma sociedade em crise. Lenira Marques Covizzi, ao delimitarnuances da significação do insólito, declara:

Um mundo em crise é um mundo não sólito (...).

Crise de valores porque a realidade convencionada, seus conceitos e representações não são mais aceitos sem dúvida. Se essa realidade é transfigurada artisticamente numa irrealidade que a contém, e se as produções artísticas contemporâneas enfatizam esta última escamoteando aquela, nada mais necessário que fazer o estudo da dosagem de ambas para apreender a significação do objeto analisado. (COVIZZI, 1978, p. 26-27)

A narrativa escrita numa época de crise de valores reflete o pensamento a respeito do fazer narrativo, que enfoca tanto os dilemas sociais quanto a constituição de um texto híbrido e consciente de seu estatuto questionador. 
Segundo Berman (1987), os cenários mundiais sofrem metamorfose e seus atores observam uma desintegração de seus papéis com o poder de interferirem apenas por meio da transcendência (Cf. BERMAN, 1987). No entanto, alguns desejam como Godofredo, ser ele mesmo, mas as constantes aparições femininas corroboram para uma perturbação, em que a personagem se alimenta dos momentos de deleite amoroso e se livra da mulher ao primeiro sinal de rotina. Assim, percebe-se que a personagem fragmentada "alimenta-se" do prazer momentâneo, vivendo pelos instantes da efêmera felicidade encontrada no prazer.

O narrador teme a rotina, matando frente ao menor vestígio de privação da liberdade, mas suas refeições, no restaurante habitual, não o deixam entediado?A cada nova ida ao restaurante, ou a cada refeição, Godofredo tornava-se o marido João de Deus de Geralda, Robério de Joana, que achava chamar-se Godofredo, e finalmente, já em sua "casa" o noivo João de Deus. Estranho, insólito, metaempírico? A cada novo nome o narrador recebe uma nova personalidade, mas o restaurante "habitual" não o incomodava, como se a ida ao restaurante fosse o estopim para sua renovação. Assim, 0 sujeito fragmentado, e em crise, ao ir jantar, ou almoçar, tornava-se outro menos culpado, portanto, livre.

Godofredo como um ser comum convive com uma diversidade de sentimentos próprios das pessoas, sobrevivendo a sensações humanas, passando por momentos relativos ao amor, à morte, à liberdade, ao tédio.Ele evoca a concretização da estruturação dos diversos episódios insólitos por todo o conto, mas não pretende encontrar respostas apenas se encontrar, enfocando sua busca no retorno ao restaurante. A personagemnem questiona, nem tenta esclarecer os acontecimentos, apenas os aceita de forma cômoda, os utiliza proveitosamente, tendo oportunidade e quando o aborrece 0 despreza e "naturaliza". Dessa forma, o narrador demonstra-se como 
um ser partido infeliz em viver com o outro, mas incompleto na solidão.

Os eventos insólitos, que irrompem no decorrer da narrativa, não apresentam provas palpáveis e muito menos que possam ser esclarecidas com base na razão, ou na lógica. Não há, também, explicações para a realidade, na qual a personagem se encontra mergulhada, pois nem o plano ordinário, nem o extraordinário são capazes de caracterizar o mundo caótico, em que sobrevive a personagem. O insólito irrompe amenizando a solidão, porém a personagem inconformada com a convivência prefere o prazer da efemeridade, aproveitando ao máximo e desprezando depois, aparentemente, usando a morte como saída, mas nem sobre isso há certeza, já que a primeira esposa retorna.

Em suma, os eventos insólitos, apesar de denunciados e percebidos como meta-empíricos, acabam incorporados ao quotidiano da personagem, sem que realmente necessitem de uma explicação ou mudança. Uma espécie de neutralização banaliza-os e os faz parecer próprios, apropriados, ainda que estranhos, àquele universo constituído no interior da diegese.

\section{REFERÊNCIAS BIBLIOGRÁFICAS:}

BRAIT, Beth. A personagem. Série Princípios. São Paulo: Editora Ática, 1985.

BELLA JOZEF. A Máscara e o Enigma - A modernidade: da representação à transgressão. Rio de Janeiro: Francisco Alves, 2006.

BERMAN, Marshall. Tudo que é sólido desmancha no ar: a aventura da modernidade. São Paulo: Cia. das letras, 1987.

CHIAMPI, Irlemar. O Realismo Maravilhoso. São Paulo: Perspectiva, 1980.

COVIZZI, Lenira Marques. O insólito em Guimarães Rosa e Borges. São Paulo: Ática, 1978. 
FURTADO, Filipe. A construção do fantástico na narrativa. Lisboa: Horizonte, 1980.

- "Fantástico (modo)". In: E - Dicionário de Termos Literários de Carlos Ceia. Lisboa: Faculdade de Ciências Sociais e Humanas (Universidade Nova de Lisboa). Disponível em: http://www.edtl.com.pt/index.php?option=com mtree\&task

$=$ viewlink\&link id=188\&It emid=2, s/n. Consultado em: 01/08/2010 às $21: 00$.

NUNES, Sandra. Biografia - Vida. Online: disponível na internet via http://www.murilorubiao.com.br. Arquivo consultado em 06 de junho de 2010.

REIS, Carlos\& LOPES, Ana Cristina M. Dicionário de Narratologia. Coimbra: Almedina, 2000.

RUBIÃO, Murilo. "Os três nomes de Godofredo". In: Contos Reunidos. São Paulo: Ática, 2005, p. 87-95.

TODOROV, Tzvetan. Introdução à Literatura Fantástica. São Paulo: Perspectiva, 1992. 